\title{
THE ONTOLOGICAL FEATURES OF VERB PHRASES IN NATIONAL GEOGRAPHIC'S VISIONS OF MARS
}

\author{
Wedhowerti \\ Sanata Dharma University, Yogyakarta, Indonesia \\ E-mail:wedho.sc@usd.ac.id
}

Received: 2021-05-05

Accepted: 2021-06-07

\begin{abstract}
Verb Phrase (VP) is one of the most important types of phrase for its function. It provides information about the subject of the sentence. Verb Phrase itself has more than one type. It also has ontological aspect, an aspect by which a certain situation is represented. This aspect is made up by features. This study aims at finding out and analyzing the types of VP and their ontological features in National Geographic's Visions of Mars. By analyzing and understanding the types of VP and their ontological features, readers understand the discourse more. They gain more perspective syntactically. This study employs syntactic approach and is qualitative in nature. The results yield three different types of VP, i.e. action, process, and state where action VP places the highest position. There are four ontological features found in Visions of Mars, i.e. dynamic, agentive, nonevolving, and evolving. The findings imply how Visions of Mars is structured. The deeds are mostly conducted or done by an agent and show prompt situations.
\end{abstract}

Keywords: Verb Phrase, ontological feature, Syntax, National Geographic

\section{Introduction}

The notion of grammar has existed since the study of language made into existence by scholars and known to people in general. In Traditional Grammar, the earliest grammar of English, there are terms as word, phrase, and clause. In Traditional Grammar itself, the "word" is basically rarely given any definition. This is caused by an assumption that people already know what a "word" is. Phrase, however, has received more attention due to its complexity. A phrase is a group of words forming a syntactic unit which is not a complete sentence, i.e. it does not have a subject or predicate (Hartmann \& Stork, 1976: 175). Further, Finch states that a phrase is formed out of the main lexical word classes. Therefore, there are noun, verb, adjective, adverb, and prepositional phrases (Finch, 2000: 112). Individual words come and cohere to form a syntactic entity in a phrase. They are able to be moved around and be substituted by another word. In the following sentences, for example, the italicized words are capable of both of these:

The climber went down Mt. Merapi.

Down Mt. Merapi went the climber (movement)

The climber went there (substitution) 
The two tests being applied here are described by Fabb as follows:

(a) if a sequence of words can be moved as a group, they may form a phrase (the movement test);

(b) if a sequence of words can be replaced by a single word, they may form a phrase (the replacement test) (2005: 3-4).

The tests above work better for some types of phrase than for others. Verb phrases, for example, are not very amenable to movement although they can be substituted for, even in a limited manner:

Jack went down the hill and the cat did too.

In this example, did is substituting for the string went down the hill, and as a consequence, it is clear for identifying it as a phrase. Each phrase has a head word, taken from the word class which forms its foundation. Quirk et al. state that among the phrases, verb phrase and noun phrase are the most important ones for functional reasons (1985: 61). $A$ verb phrase operates as the $V($ Verb) element in a clause, i.e. the most central and essential part of the clause as in He (S) should keep (V) all the books (O) in his bag (A).

A verb phrase (VP) will have a verb as its head. A verb phrase can be defined as the part of a sentence which contains the main verb and also any objects, complements, and adverbs (Richards \& Schmidt, 2002: 578), In other words, a VP is a syntactic structure containing the predicative elements of a sentence. It functions to provide information about the subject of the sentence. Based on the definition, a verb phrase consists only of the main verb, auxiliary verb, and other infinitive or participle. For example, in the following sentences only the italicized words would be considered to form the verb phrase for each sentence:

(a) The king gave the commander a sword.

(b) The small animals were being eaten alive.

(c) Jane kept singing like a singer having a concert.

Verb phrase has aspects. Aspects are categories used in the description of verbs (Finch, 2000: 85). Further, Declerck, Reed \& Cappelle state that aspects are different ways of viewing the internal constitution of an actualizing situation (2006). These different ways are expressed by different markers on the verb, i.e. suffixes, auxiliaries, or a combination of the two (Declerck et al., 2006: 28). In this case, situation refers to anything that can be denoted by a verb phrase, i.e. actions, events, states, and process. There are several aspects that VP has. There are perfective, progressive, ontological aspects (Declerck et al., 2006: 49). So far, people are more familiar with the two former aspects. However, there is some more we could explore from the existence of VP and what it represents. This is how ontological aspect plays its role. Traditionally, it is also called lexical aspect. Ontological aspect concerns about how lexical material in the verb phrase determines one or more inherent characteristics of a kind of situation (Declerck et al., 2006: 29). Further, they elaborate that ontological aspect is the expression of inherent characteristics, such as (non) staticness, (non) durativeness, etc., of a kind of situation as it is linguistically represented by a verb phrase that has not yet been marked for progressive or nonprogressive aspect. (By 'inherent' we mean that the kind of situation necessarily has the features in question, irrespective of the context in which it is used) (2006: 49). 
Linguists move ahead to analyze this aspect. Lyons (1977) and Declerck et al. (2006) are among linguists who propose theories on features making up the ontological aspect. This aspect shows us how the lexical choice, i.e. the verb phrase choice represents different situation other than being progressive like what is discussed in progressive aspect.

Regarding the representation of different situation as mentioned above, each verb phrase in any sentences of different sources is worth studying. By analyzing the ontological aspect represented by a VP or VPs, it is expected that readers understand a discourse more. This understanding entails the knowledge of different situations that VPs represent.

One of the sources of famous discourse is National Geographic (NG). This magazine is managed and published by a non-profit organization. It uses its science power for education and illuminating the world. The contribution that it made was concerning the exploration of space science. The development of space science is very exciting for scholars and space enthusiasts. An interesting topic of space science is the Red Planet or Mars. This topic has been in high popularity due to people's curiosity on how Mars is. One of the National Geographic's editions discussing how Mars is Vol. 214, December 2008 entitled Visions of Mars.

This study has significant benefit to readers to go deeper into verb phrases in order to find out the different situation that the writer/contributor of National Geographic presented. Approaching a discourse about Mars using Syntax is also beneficial to other scholars for more linguistic perspectives.

In response to the benefit above, two research questions are formulated in this study as follows: 1) What types of VP are found in National Geographic's Visions of Mars?; and 2) What features are used by the VP to represent different situation in National Geographic's Visions of Mars?

\section{Literature Review}

Past studies suggested that VPs were analyzed by exploring their construction or structure, constituent, and function (Rodríguez-Navarro, 2002; Uswar, 2018). RodríguezNavarro observed VPs from their morphologic modification and syntactic complementation (2002). He explained that morphologic modification of the VPs includes mood, tense, aspect, polarity, and voice. He further elaborated that both morphologic modification and syntactic complemention were complementary to each other (2002). His study focused on morphologic modification and syntactic complementation where progressive and nonprogressive aspect of VPs are included in the discussion, while this study focuses on ontological aspect of VPs.

The second related study was on the constituent of VPs and the construction of VPs of Link Magazine using Radford's X-bar theory (Majid, 2015). The study yielded that among 70 VPs in the Link Magazine, Verb (Head) + Post-modifier construction placed the highest occurrence or $84 \%$. The second study is different from this study in terms of its procedure. The second study focused on the external relations of the VPs, while this study focuses on the internal relations of the VPs.

The formation and function of VPs in English and Minang became the focus of the third study (Uswar, 2018). Uswar suggested that the formation of VPs in English was Vcop + NP, Vcop + AP, and Vcop + PP, while the function of VPs was to form the head phrase (2018). This third study is different from this study in the light of its research procedure as in the second study. The third study highlighted the external relations of the VPs seen from VPs formation and function. 
In relation to this study, the grant theories of ontological features by Declerck et al. (2006: 53-65) and Lyons (1977: 483-486) are employed. These are chosen to base the analysis of the VPs found in National Geographic's Vision of Mars. The theories are elaborated as follows.

\subsection{Ontological Feature 1: Static and Dynamic}

Both Declerck, et.al. and Lyons provide similar definition of static situation or state. It is a situation which is conceived of and represented as existing rather than as being done, taking place or developing, and as being unchanging and hence homogeneous throughout its duration (Declerck, et al., 2006: 51), (Lyons, 1977: 483). A static kind of situation is not agentive. It means, it is not performed, done, conducted nor initiated by an agent. An agent is, any entity that is capable of operating upon other entities, effecting some change in their properties or their location; an animate being is one that is able to move itself without the intervention of any external agency (Lyons, 1977: 483). It does not require any drive to continue. "George is a rich businessman" is classified as static.

Any situations that are not static are classified as non-static situation is or dynamic. There are three types of non-static or dynamic situation, i.e. action, event, and process. If a dynamic situation is under control of an agent, it is an action. Any non-static situation that is temporary is called an event. If it continues or being extended, then it is called a process.

John writes a poem is an action. While John fell off the stairs is an event. An event is a dynamic kind of situation which is not controlled by an agent but just it happens, e.g. bursting, exploding, falling off something and, snowing. The population diminished rapidly is a process. A process includes changing or developing. Certain verbs can only be used to refer to a state or state verbs, for example seem, contain, know, and consist of. The verb be can be used both in a static and in a dynamic manner. It depends on whether it is agentive or not. To summarize the four types of verbs, Table 1 below illustrates them.

\begin{tabular}{|l|l|}
\hline Type & \multicolumn{1}{|c|}{ Examples } \\
\hline Process & $\begin{array}{l}\text { Change, improve, thicken, diminish, grow, develop, } \\
\text { increase }\end{array}$ \\
\hline Action & Drink, eat, abandon, write, ask, play, read \\
\hline Event & Explode, rain, happen, snow, befall, burst, occur \\
\hline State & Have, seem, prefer, belong, know, contain, consist of \\
\hline
\end{tabular}

Table 1. Four Types of Verbs

\subsection{Ontological Feature 2: Agentive and Non-Agentive}

A situation is agentive if it is performed, done, or conducted by an agent. John kicks George is agentive. John is the agent. There are three types of agent. First is animate agent like John. The second is non-human agent as in My dog bit a neighbor. The third is inanimate agent as in The exam starts at 8.30.

A state is by definition non-agentive. Therefore, Jack is an old person does not imply that Jack does something in order to achieve the effect of being an old person. Any dynamic situations that are developments can be non-agentive as in A tree fell down (event) and The wall changed its color (process). While, actions are agentive. They are performed by an agent as in George opens the window.

Some actions however, require different analysis. Some linguists observe that an action is performed consciously, volitionally, deliberately or intentionally in their definition of agentivity. Thus, Bussmann, defines agent as the semantic role (thematic relation) of the 
volitional initiator or causer of an action (1999: 11). Further, Brinton (2000: 279) writes that these sentences e. g. Orlando cooled the water, Orlando made the water cool, Orlando caused the water to become cool are agentive, involving a human agent who intentionally brings about a change in state in an entity (2000: 279).

\subsection{Ontological Feature 3: Evolving and Non-Evolving}

A VP may or may not represent a type of situation which is gradually developing or evolving. Jack drew a line is agentive, dynamic, however, it is not evolving. Meanwhile, The street strike got worse is non-agentive, dynamic, and evolving.

Evolving situations are dynamic, durative, and non-agentive, in gradual change (Declerck et al., 2006: 65). Prompt situations are not evolving. Any evolution does not happen at once. States, on the other hand, are not evolving either. An evolution includes changes while states are unchanging. The situation of [-evolving] into [+evolving] is found in It died and It was dying. The first VP is a prompt transition and non-evolving. The second VP represents a situation which is non-static, non-agentive, and gradually. All of the ontological features mentioned above are summarized in Table 2 below.

\begin{tabular}{|c|c|c|c|}
\hline & Static & Evolving & Agentive \\
\hline State & $\mathrm{V}$ & $\times$ & $\times$ \\
\hline Action & $\times$ & $\times$ & $\mathrm{V}$ \\
\hline Process & $\times$ & $\mathrm{V}$ & $\mathrm{V} / \times$ \\
\hline Event & $\times$ & $\times$ & $\times$ \\
\hline
\end{tabular}

Table 2. Ontological Features

\section{Research Method}

This study employed syntactic approach to find out the ontological features of ten verb phrases. The data were taken purposively by sorting sentences which only had one verb phrase. All sentences were taken from National Geographic's Vision of Mars (December 2008: 92). After that, ten verb phrases were obtained and analyzed.

This study is qualitative in nature. George mentions that qualitative research is any research whose results are explained and elaborated in words (2008). The results of this research will be in words in the light of explanation in the Results and Discussion section. Each datum will be presented in a table containing number of the datum, the VP, and the sentence where the VP was taken from. Then, the discussion of each datum is provided after each table.

After the discussion of each datum, the summary of all features will be presented in figures. This is required in order to show the pattern of each feature. The pattern is shown through the percentage of features' occurrence.

\section{Results and Discussion}

Before analyzing the ten data, the sentences where ten verb phrases are taken from presented in Table 3 below. After that, each analysis will be presented in turn following Tables 4 - 13.

\begin{tabular}{|l|l|l|}
\hline No. & Verb Phrase & \multicolumn{1}{c|}{ Sentence } \\
\hline Datum 1 & To exert & Mars has long exerted a pull on the human imagination \\
\hline Datum 2 & To see & $\begin{array}{l}\text { The erratically moving red star in the sky was seen as sinister } \\
\text { or violent by the ancients }\end{array}$ \\
\hline
\end{tabular}




\begin{tabular}{|l|l|l|}
\hline Datum 3 & To identify & The Greeks identified it with Ares, the god of war \\
\hline Datum 4 & To name & $\begin{array}{l}\text { The Babylonians named it after Nergal, god of the } \\
\text { underworld }\end{array}$ \\
\hline Datum 5 & To call & The ancient Chinese called it Ying Huo, the fire planet \\
\hline Datum 6 & To continue & $\begin{array}{l}\text { The eccentricity of Mars's celestial motions continued as a } \\
\text { puzzle until 1609 }\end{array}$ \\
\hline Datum 7 & To analyze & $\begin{array}{l}\text { In that year, Johannes Kepler analyzed all the planetary orbits } \\
\text { as ellipses, with the sun at one focus }\end{array}$ \\
\hline Datum 8 & To observe & $\begin{array}{l}\text { In that same year Galileo first observed Mars through a } \\
\text { telescope }\end{array}$ \\
\hline Datum 9 & To improve & $\begin{array}{l}\text { By the mid-17th century, a scientist had improved the } \\
\text { telescopes }\end{array}$ \\
\hline Datum 10 & To observe & $\begin{array}{l}\text { The Italian astronomer Giovanni Cassini observed certain } \\
\text { features accurately enough to calculate the planet's rotation }\end{array}$ \\
\hline
\end{tabular}

Table 3. List of Ten Data

\begin{tabular}{|l|l|l|}
\hline No & Verb Phrase & \multicolumn{1}{c|}{ Sentence } \\
\hline Datum 1 & To exert & Mars has long exerted a pull on the human imagination \\
\hline
\end{tabular}

Table 4. Datum 1

According to The American Heritage Dictionary, to exert means to put to use or effect (2018: 2590). The VP above is dynamic because it is done. The action to exert is done by an agent. In this case, the agent is Mars. Although it is not animate, it might be attributed an agentivity. The VP is non-evolving because to exert does not imply gradual development. This VP is dynamic, non-evolving, and agentive.

\begin{tabular}{|l|l|l|}
\hline No & Verb Phrase & \multicolumn{1}{c|}{ Sentence } \\
\hline Datum 2 & To see & $\begin{array}{l}\text { The erratically moving red star in the sky was seen as sinister or } \\
\text { violent by the ancients }\end{array}$ \\
\hline
\end{tabular}

Table 5. Datum 2

When we categorize the VP, we observe that it belongs to a state because the verb see is the same as know, seem, and contain. However, when we analyze the sentence above, its VP implies another possibility, that it is categorized as a dynamic VP as well. It is so because of the existence of the agent. As mentioned in the earlier discussion that certain static situation verbs can be used both in a static and dynamic manner depending on whether the situation which it helps to describe is agentive or not.

Therefore, it is concluded that the situation of Datum 2 above is dynamic. The agent doing the action is the ancients. They see the moving red star in the sky. The VP does not represent an evolving situation. The activity of seeing does not gradually develop. Therefore, it is not evolving. This VP is summarized as dynamic, non-evolving, and agentive.

\begin{tabular}{|l|l|l|}
\hline No & Verb Phrase & \multicolumn{1}{c|}{ Sentence } \\
\hline Datum 3 & To identify & The Greeks identified it with Ares, the god of war \\
\hline
\end{tabular}

Table 6. Datum 3

The third sentence consists of a VP which is dynamic, agentive, and non-evolving. It is dynamic because the activity of identifying the red planet is done and not a situation which already exists. The activity of identifying is done by an agent, the Greeks. Finally, it is said to 
be non-evolving because the activity of identifying does not gradually develop and the VP is an action one.

\begin{tabular}{|l|l|l|}
\hline No & Verb Phrase & \multicolumn{1}{|c|}{ Sentence } \\
\hline Datum 4 & To name & The Babylonians named it after Nergal, god of the underworld \\
\hline
\end{tabular}
Table 7. Datum 4

The VP above is classified under the action VP. It is dynamic for it is done or actualized under the controlled of an agent. The agent is the Babylonians. The activity of naming the red planet is not gradual. Therefore, it is non-evolving. It is summarized as dynamic, agentive, and non-evolving.

\begin{tabular}{|c|l|l|}
\hline No & Verb Phrase & Sentence \\
\hline Datum 5 & To call & The ancient Chinese called it Ying Huo, the fire planet \\
\hline
\end{tabular}

Table 8. Datum 5

Like other VPs mentioned before, this VP is an action VP. It is dynamic for it is done by an agent namely the ancient Chinese. The activity of calling the red planet does not reveal any gradual development. The activity is not gradually done. Thus, it is non-evolving. It is then summarized as dynamic, agentive, and non-evolving.

\begin{tabular}{|l|l|l|}
\hline No & Verb Phrase & \multicolumn{1}{|c|}{ Sentence } \\
\hline Datum 6 & To continue & $\begin{array}{l}\text { The eccentricity of Mars's celestial motions continued as a } \\
\text { puzzle until 1609 }\end{array}$ \\
\hline
\end{tabular}

Table 9. Datum 6

The VP in the sentence above is also an action one. The activity of continuation is actualized by an agent. Thus, the VP is classified as dynamic. The case of the agentivity is the same as the in the first sentence where the agent is not animate. It is possible that it is attributed an agentivity. Therefore, the act of continuing is done by the eccentricity of Mars's celestial motions. The VP is non-evolving because it is dynamic and an action one. The VP is not a process VP although there is an adverb of time (1609) and it requires a duration. The process of continuing is not a gradual development. It does not undergo any changes at all. This VP is attributed as dynamic, agentive, and non-evolving.

\begin{tabular}{|l|l|l|}
\hline No & Verb Phrase & \multicolumn{1}{c|}{ Sentence } \\
\hline Datum 7 & To analyze & $\begin{array}{l}\text { In that year, Johannes Kepler analyzed all the planetary orbits as } \\
\text { ellipses, with the sun at one focus }\end{array}$ \\
\hline
\end{tabular}

Table 10. Datum 7

The seventh VP is an action VP. It is dynamic because it is actualized and performed by Kepler, the agent. The activity of analyzing all the planetary orbits as ellipses is done without any gradual development regardless of how long it takes to perform the action. Therefore, the VP is non-evolving. This seven datum is summarized as dynamic, agentive, and nonevolving.

\begin{tabular}{|l|l|l|}
\hline No & Verb Phrase & Sentence \\
\hline Datum 8 & To observe & In that same year Galileo first observed Mars through a telescope \\
\hline
\end{tabular}

Table 11. Datum 8

The VP above is an action VP. There is an agent performing the action. The agent is Galileo. He observed Mars through a telescope. He makes the action realized. Thus, this VP is 
dynamic. The activity of observing Mars is done without any gradual development. Therefore, it is non-evolving. It is attributed as dynamic, agentive, and non-evolving.

\begin{tabular}{|l|l|l|}
\hline No & Verb Phrase & \multicolumn{1}{c|}{ Sentence } \\
\hline Datum 9 & To improve & By the mid-17th century, a scientist had improved the telescopes \\
\hline
\end{tabular}

Table 12. Datum 9

The VP above is a process. Improve involves incremental change that implies a scale of some sort. This means that each stage of a process is similar to the preceding stage, except that it usually represents a higher or lower value on a scale. This process verb emphasizes that the subsequent stages of the process correspond with different quantificational values on the scale, in this case, it is above the preceding scale. The American Heritage Dictionary defines to improve as to raise to a more desirable or more excellent quality or condition; make better or to increase the productivity or value of...(2018: 3664). The VP implies that telescopes have reached a better scale of condition compared to the previous time.

As mentioned before, the process VP is not agentive for some examples because the process is considered as dynamic situation which develops. This process VP is agentive because there is a causer that makes the situation happen. The causer is a scientist who then acts as an agent. The VP is classified as evolving. It gradually develops from a certain scale to another scale. The telescopes' quality changes from a certain quality (less good) to something better. The VP is then attributed as evolving, agentive, and dynamic.

\begin{tabular}{|l|l|l|}
\hline No & Verb Phrase & \multicolumn{1}{c|}{ Sentence } \\
\hline Datum 10 & To observe & $\begin{array}{l}\text { The Italian astronomer Giovanni Cassini observed certain } \\
\text { features accurately enough to calculate the planet's rotation }\end{array}$ \\
\hline
\end{tabular}

Table 13. Datum 10

The tenth VP is classified as an action VP. It is performed by an agent, the Italian astronomer Giovanni Cassini. He observed certain features accurately, therefore the VP is dynamic. Like other action VPs, it is non-evolving. The activity of observing does not undergo any gradual development. It does not imply certain stages or scales. This VP is summarized as dynamic, non-evolving, and agentive.

To summarize, all ten data are presented in Table 14, Table 15, Figure 1, Figure 2 , Figure 3 , and Figure 4 below. Table 14 shows the number of occurence of each ontological feature where Evolving occupies the lowest number. It occurs once or $3.3 \%$. Both Dynamic and Agentive have the same number or $33.3 \%$ each and occupy the highest occurence. NonEvolving occupies the second rank as it has $30 \%$.

Besides showing occurences of each ontological feature, Table 14 also summarizes all findings related to features that each VP represents. Ten data (Datum 1, Datum 2, Datum 3 , Datum 4, Datum 5, Datum 6, Datum 7, Datum 8, Datum 9, and Datum 10) all represent Dynamic. The same thing is also true to Agentive where all ten data represent. Non-Evolving is represented by nine data (Datum 1, Datum 2, Datum 3, Datum 4, Datum 5, Datum 6, Datum 7, Datum 8, and Datum 10). The last is Evolving where it is represented by one datum only (Datum 9). All information in Table 14 is then elaborated in Figure 1 and Figure 2.

Table 15 states the information about the type of VP. There are three types of VP in National Geographic's Visions of Mars: action, process, and state. Almost all VPs are action. There are eight data belonging to action VP. Those are datum 1 (to exert), datum 3 (to identify), datum 4 (to name), datum 5 (to call), datum 6 (to continue), datum 7 (to analyze), datum 8 (to observe), and datum 10 (to observe). One datum is classifed as state VP namely 
datum 2 (to see). The last type is process where one datum is classified as belonging to it. Datum 9 (to improve) is process VP. All information in Table 15 is elaborated in Figure 3 and Figure 4.

\begin{tabular}{|c|c|c|c|c|}
\hline Feature & Datum (D) & Verb Phrase (VP) & Number & Percentage (100\%) \\
\hline Dynamic & $\begin{array}{l}\text { D 1, D 2, D 3, } \\
\text { D 4, D 5, D 6, } \\
\text { D 7, D 8, D 9, } \\
\text { D } 10\end{array}$ & $\begin{array}{l}\text { To exert, to see, to identify, } \\
\text { to name, to call, to continue, } \\
\text { to analyze, to observe, to } \\
\text { improve, to observe }\end{array}$ & 10 & 33.3 \\
\hline Agentive & $\begin{array}{l}\text { D 1, D 2, D 3, } \\
\text { D 4, D 5, D 6, } \\
\text { D 7, D 8, D 9, } \\
\text { D } 10\end{array}$ & $\begin{array}{l}\text { To exert, to see, to identify, } \\
\text { to name, to call, to continue, } \\
\text { to analyze, to observe, to } \\
\text { improve, to observe }\end{array}$ & 10 & 33.3 \\
\hline Non-Evolving & $\begin{array}{l}\text { D 1, D 2, D 3, } \\
\text { D 4, D 5, D 6, } \\
\text { D 7, } \\
\text { D 8, D } 10\end{array}$ & $\begin{array}{l}\text { To exert, to see, to identify, } \\
\text { to name, to call, to continue, } \\
\text { to analyze, to observe, to } \\
\text { observe }\end{array}$ & 9 & 30 \\
\hline Evolving & D 9 & To improve & 1 & 3.3 \\
\hline
\end{tabular}

Table 14. The Summary of Ontological Features Occurence

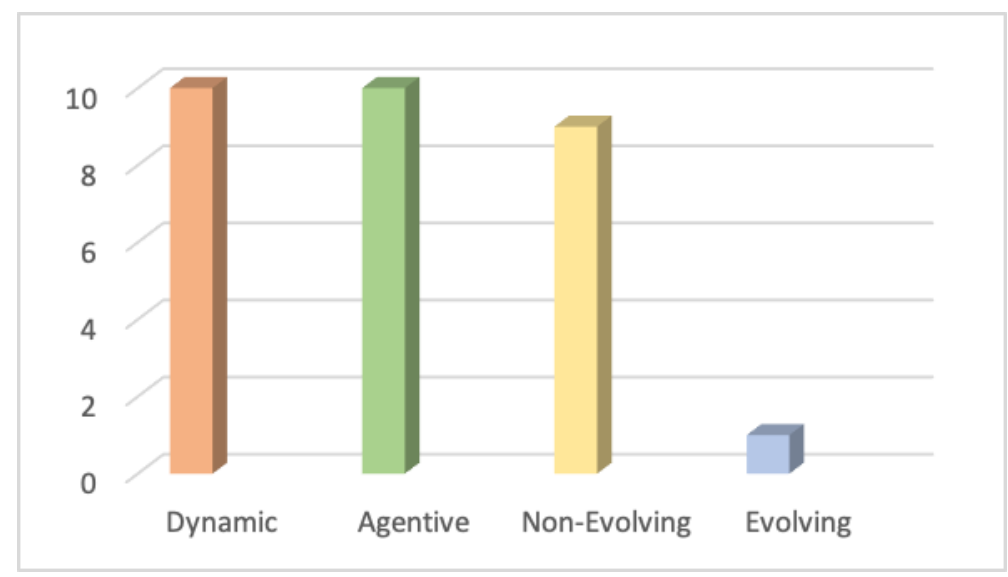

Figure 1. Number of Occurence of Each Ontological Feature

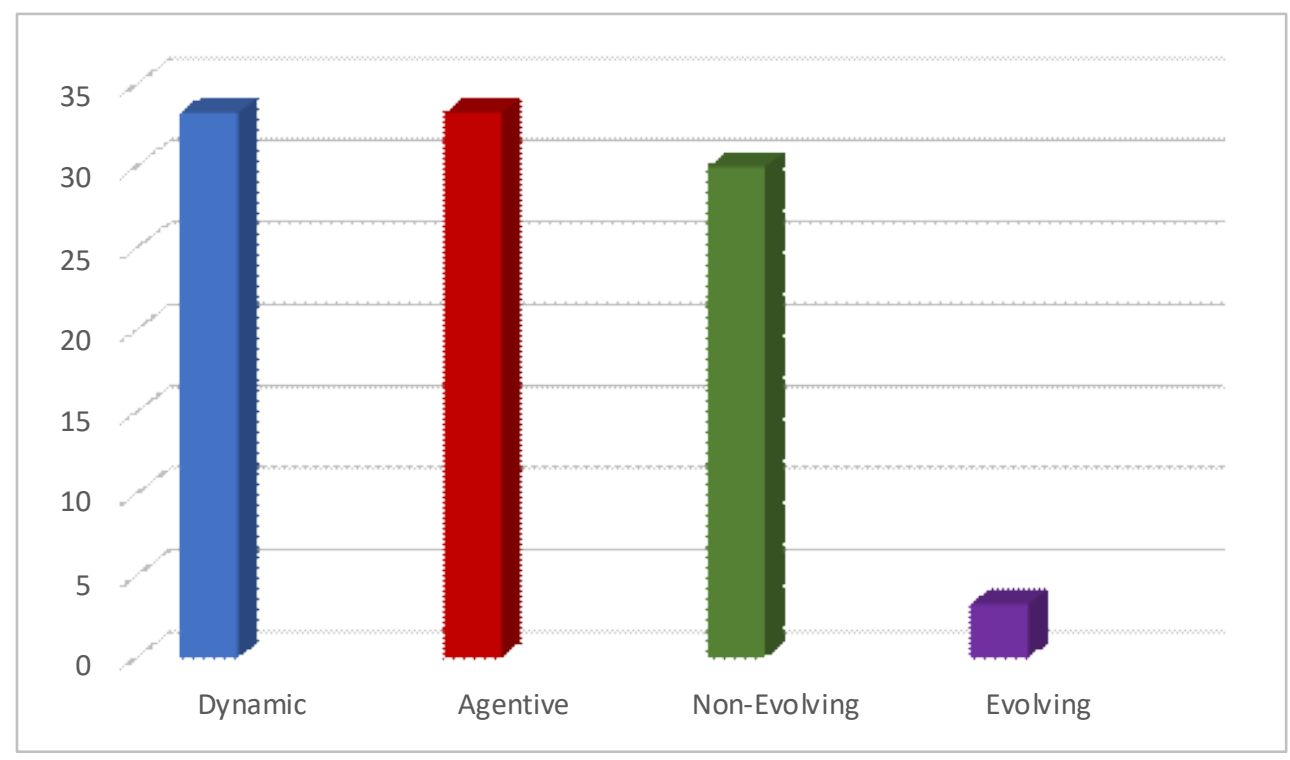

Figure 2. Percentage of Occurence of Each Ontological Feature 


\begin{tabular}{|l|l|l|c|c|}
\hline Type of VP & \multicolumn{1}{|c|}{ Datum (D) } & \multicolumn{1}{|c|}{ Verb Phrase (VP) } & Number & Percentage (100\%) \\
\hline Process & D 9 & To improve & 1 & 10 \\
\hline State & D 2 & To see & 1 & 80 \\
\hline Action & D 1, D 3, D 4, D & $\begin{array}{l}\text { To exert, to identify, to } \\
\text { name, to call, to } \\
\text { 5, D 6, D 7, D 8, } \\
\text { D 10 }\end{array}$ & $\begin{array}{l}\text { continue, to analyze, to } \\
\text { observe, to observe }\end{array}$ & 8 \\
\hline
\end{tabular}

Table 15. The Summary of Types of Verb Phrase

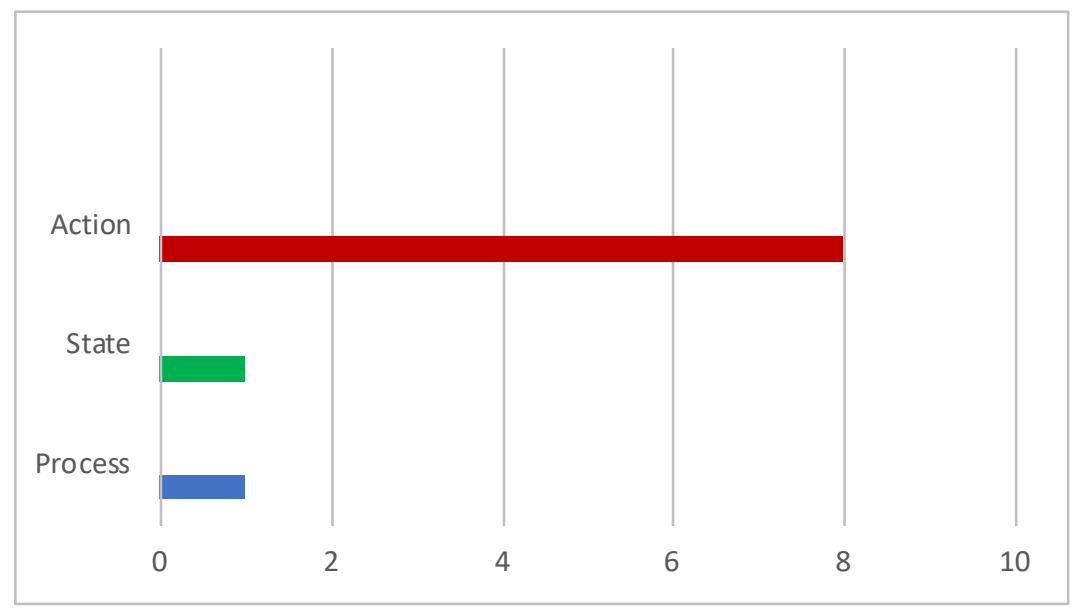

Figure 3. Number of Occurence of Each Type of Verb Phrase

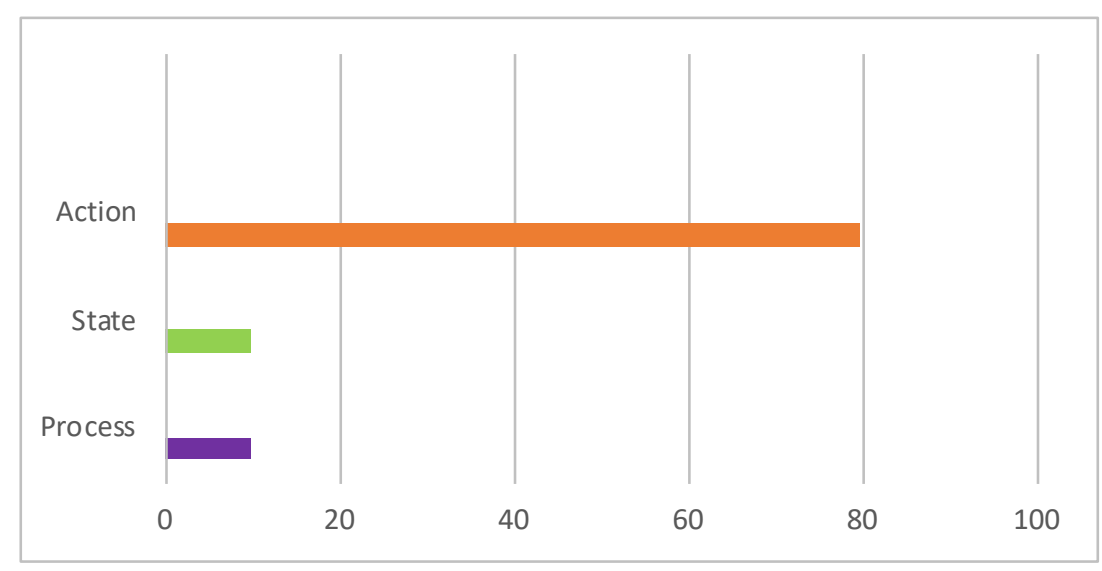

Figure 4. Percentage of Occurence of Each Type of Verb Phrase

\section{Conclusion}

The Verb Phrases (VPs) in National Geographic's Visions of Mars have three different types, i.e. action, process, and state. There are eight data belonging to action VP. The eight VPs are to exert, to identify, to name, to call, to continue, to analyze, to observe, to observe. They are classified as action VPs because they are conducted or realized by an agent. The second type is process. The VP to improve is categorized as a process VP. It is because to improve implies a development in certain scale. The last type is state. To see belongs to state VP because it is related to sense.

There are four ontological features found in the VPs. The first feature is dynamic as in to exert, to see, to identify, to name, to call, to continue, to analyze, to observe, to improve, to 
observe. These VPs implies something that has not existed before. Things are done and made to happen. The second feature is agentive as in to exert, to see, to identify, to name, to call, to continue, to analyze, to observe, to improve, to observe. The deeds as implied in the VPs are conducted or done by an agent. The next feature is non-evolving. To exert, to see, to identify, to name, to call, to continue, to analyze, to observe include in non-evolving because they show prompt situations or conditions which do not need gradual development. Finally, the last feature is evolving. Contrary to non-evolving, this feature shows any gradual development. Therefore, the VP to improve is classified as evolving since it represents changes from previous or existing situation.

Understanding the features of VPs provide more understanding on a discourse. More discourses are waiting to be analysed using syntactic approach. This, in turn, gives birth to more syntactic perspectives in the future. Therefore, future research and researchers are expected to work more on different types of discourse employing syntactic approach.

\section{References}

Brinton, L. J. (2000). The Structure of Modern English: A Linguistic Introduction. Amsterdam: John Benjamins.

Bussmann, H. (1999). Dictionary of Language and Linguistics. New York: Routledge.

Declerck, R., Reed, S. \& Cappelle, B. (2006). The Grammar of the English Verb Phrase: A Comprehensive Analysis. Berlin: Mouton de Gruyter.

Fabb, N. (2005). Sentence Structure. London: Routledge.

Finch, G. (2000). Linguistic Terms and Concepts. New York: St. Martin's Press.

Hartmann, R.R.K. \& Stork, F.C. (1972). Dictionary of Language and Linguistics. London: Applied Science Publishers.

Lyons, J. (1977). Semantics. Cambridge: Cambridge University Press.

Majid, K. (2015). Syntactic Analysis of Verb Phrase Found in the Text of Link Magazine the Fourth Edition August 2011 (Unpublished undergraduate thesis). State Institute for Islamic Studies (STAIN), Salatiga

National Geographic Society. (2008). National Geographic, Vol 214, No. 6. New York: National Geographic Society.

Quirk, R., Greenbaum, S., Leech, G., \& Svartvik, J. (1985). A Comprehensive Grammar of the English Language. London: Longman

Richards, J.C \& Schmidt, R. (2010). Longman Dictionary of Language Teaching and Applied Linguistics. London: Pearson Education Limited.

Rodríguez-Navarro, L. Q. (2002). Verb Phrases and Noun Phrases in English: A Parallel Approach. In M. Carretero González, E. Hidalgo Tenorio, N. McLaren \& G. Porte (Eds), A Life in Words (pp. 247-266). Granada: Editorial Universidad de Granada.

The American Heritage Dictionary of the English Language. (2018). Boston: Houghton Mifflin Company.

Uswar, Y. (2018). Verb Phrase in English and Minang Language. Medium for English Language Teaching, 3 (1), 83-100 DOI: http://dx.doi.org/10.22303/melt.3.1.2018.6479 